\title{
EL SIGNIFICADO DE CORONA DE ARAGÓN (CONTRARRÉPLICA)
}

\author{
Jesús Lalinde Abadia
}

A partir del XIII Congreso de Historia de la Corona de Aragón, celebrado en 1987. he promovido una depuración histórica del concepto de $\mathrm{Co}$ rona de Aragón partiendo de su denominación, algo que no había sido intentado por nadie. El indicado proceso de depuración histórica no lo considero cerrado, ni posiblemente lo consideraré así nunca, puesto que en cualquier momento pueden surgir nuevas aportaciones documentales con incidencia en él. El paso más importante de mi parte lo considero el dado con mi intervención en una reunión científica celebrada en Zaragoza el año $1992^{1}$, pero que todavía no ha sido publicada. Me es grato reconocer que algunas matizaciones importantes contenidas en la referida intervención fueron posibles merced a una réplica del profesor Juan Manuel del Estal, formulada en el curso de una ponencia desarrollada por mí en el XIV Congreso de Historia de la Corona de Aragón, celebrado en 1990, y así consta en dos de mis trabajos sobre el tema aún no publicados. Siempre he sentido gran respeto por la laborosidad investigadora del profesor Juan Manuel del Estal y lo seguiré sintiendo, aunque no puedo por menos que disentir totalmente con lo manifestado por él en un artículo sobre «Antiguedad del concepto y denominación "Corona de Aragón" s², y es ese disentimiento el que voy a exponer a continuación.

En el referido artículo, J.M. del Estal afirma que la expresión literal Corona de Aragón había sido ya explícitamente formulada en $1296^{3}$. pero sorprende cuando a continuación reconoce que la expresión utilizada había sido la de Corona del reino de Aragón ${ }^{4}$. Asegura que para Jaime II en 1296, la Corona de Aragón había sido la unidad políica territorial de todos los es-

1 Organizada por la institución Fernando el Católico, la reunión se celebró bajo el lema La Corona de Aragón y el Mediserráneo. El título de mi aportación fue el de «Depuración histórica del concepto de Corona de Aragóns.

${ }^{2}$ El trabajo ha sido publicado en Medievalia, 10, Barcelona, 1992, pp. 133-168.

3 Op. cit., p. 133.

${ }^{4}$ fd. ib, p. 135. 
tados existentes bajo su jurisdicción soberana, pero esto es algo que, en todo caso, será una inferencia del historiador, ya que el rey no ha dicho nada de eso expresamente y difícilmente hubiera podido hablar Jaime II de jurisdicción soberana ${ }^{5}$. J.M. del Estal sigue infiriendo por su cuenta al asegurar que Jaime II equiparó Corona y reino, lo que contradiría su anterior tesis de que Corona era una unidad territorial de estados y no uno sólo de éstos, máxime cuando después considera que Corona es una confederación, pues, entonces, no podía ser un reino. La confusión en la que desemboca J.M. del Estal es de tal magnitud que para él la forma política de Cataluña ha podido ser la de una procuración general, cuando es inimaginable que pueda establecerse una confederación entre uno o varios reinos y una procuración general 6 .

Creo que es apreciable la labor investigadora del profesor J.M. del Estal e insisto en que me ha obligado a introducir matizaciones en mi tesis inicial, algo que, por otra parte, consideré previsible, pero también creo que utiliza diez documentos de forma simplista y voluntarista ${ }^{7}$, en lugar de practicar un análisis conforme a rigurosos presupuestos metodológicos ${ }^{8}$. Es lo que voy a tratar de demostrar a continuación, advirtiendo que me abstendré de observar posiciones dogmáticas, por cuanto repetidamente he insistido en que mi tesis sobre una depuración histórica del concepto de $\mathrm{Co}$ rona de Aragón podrá ser rectificada, y de hecho ya lo ha sido, en cuanto aparezcan nuevos elementos de juicio, que pueden hacerlo en cualquier momento, pero, en cuanto sean aducidos también sin dogmatismo.

El profesor J.M. del Estal apoya su postura en diez documentos, lo que es lícito en cuanto que sean los más representativos y sin que pueda exigírsele que sean doce, catorce a cualquier atro número. Lo que ya no parece tan comprensible es que si el principal protagonista en su tesis va a ser Jaime II pase por alto una colección documental tan decisiva como la de H. Finke, en la que nada menos que se contiene la correspondencia diplomática del referido protagonista entre 1291 y $1327^{\circ}$. Si, como parece, ni siquiera en el índice de la obra aparece el término Corona de Aragón, habrá que dar alguna explicación de esa ausencia o, al menos, experimentar alguna duda, pero lo que no puede hacerse es silenciarla. Aun en el supuesto de que Corona de Aragón apareciera en diez documentos, que no aparece, ¿es que diez docu-

${ }^{5}$ Id. ib. Es sobradamente conocida la vinculación del término soberania a la obra de Jean Bodin en el siglo xvi.

${ }^{6}$ Vid. op. y loc. cit. Mientras el Reino pertenece al mundo de las formas políticas, la Procuración general lo es al de la Administración. Respecto a Cataluna, se ha discutido en torno a términos como el de Principado, pero nadie ha pensado en atribuirle la condición política de Procuración general.

${ }^{7}$ Me refiero a los que utiliza en el trabajo citado en nota 2.

${ }^{8} \mathrm{He}$ insistido mucho en el indicado aspecto y puede verse «Presupuestos metodológicos para el estudio institucional de las Cortes medievales aragonesasn, Medievalia, 3, Barcelona, 1982. pp. 53-79.

9 Heimrich FInKE, Acta Aragonensia, 10mo i, Berlín-Leipzig, 1908. 
mentos pueden decidir una tesis por encima del silencio de una masa documental bastante más amplia? Podría ser que la fórmula Corona de Aragón fuera apta para el interior y no para el exterior, pero en ese caso sería muy interesante constatarlo y explicar el porqué. En todo caso, lo que no es posible es decir que como Corona de Aragón aparece en diez documentos (que no aparece), ya puede ploclamarse que la denominación de la forma política ha sido esa.

Según el profesor del Estal, la expresión literal Corona de Aragón, que luego no resulta ser esa, ha aparecido en 1296, pero en este caso se queda corto, pues hay quien afirma que ha sido en 1230 , aunque la impresión que se obtiene es que la expresión aparecida ha sido también la de Corona del Reino de Aragón ${ }^{10}$. Si J.M. del Estal manifiesta que la fórmula ha aparecido en 1296 reconoce mi tesis en parte, pues eso significa que no ha nacido con el matrimono de Petronila y Ramón Berenguer. En todo caso, J.M. del Estal no se preocupa de determinar qué es lo que ha pasado antes de 1296, ni tampoco por qué la fórmula ha aparecido en 1296 . Indica que esa es la fecha en la que Jaime II de Aragón sometió a su corona el reino castellano de Murcia, pero no creo que sugiera que el nacimiento de la fórmula Corona de Aragón hubiera estado vinculado a la incorporación de un reino como el de Murcia.

Mi tesis ha sido la de que la unión de tierras bajo el poder del rey de Aragón no ha tenido denominación específica, pero que la expresión más generalizada y expresiva ha sido la de Reinos y tierras del rey de Aragón ${ }^{11}$, pero esto no ha sido tomado en consideración por J.M. del Estal. Con actitud voluntarista, diez documentos le bastan para proclamar que Corona de Aragón ha sido la denominación de la unidad territorial de los estados bajo la jurisdicción soberana de Jaime II y no se preocupa de rechazar cualquier otra posibilidad que se le ofrezca.

Si se entra en el análisis del anexo documental, creo que se patentiza el simplismo y el voluntarismo a que se ha hecho referencia. Formalmente, la presentación de los diez documentos que lo integran ofrece la corrección a la que nos tiene acostumbrados el profesor J.M. del Estal en cuanto a datación, origen del documento, transcripción, etc., pero materialmente el resultado es radicalmente opuesto. En el documento 1 se nos dice que

${ }^{10}$ En mi trabajo citado en nota 1 , y en la nota 17 del trabajo, me he referido a las dudas que ofrece el texto primitivo de la Carta de Franquicias para el Reino de Mallorca, cuya versión latina ha debido referirse a la Corona del Reino de Aragón, en tanto que según Antoni Mut Calafell la versión catalana lo ha hecho a Corona de Aragón. Es de presumir que la versión latina haya sido anterior a la catalana.

11 Vid. «La disolución de la Corona de Aragón en la Monarquía hispana o católica (s. Xvi a XVIII)». XVI Congresso di Storia della Corona d'Aragona (Sassari-Alghero 19-24 mayo 1990). vol. 1, Relazioni, Carlo Delfino Editore, Sassari, 1993, pp. 155-176, y, sobre todo, Rey, Conde y Seriar (El nacionalisma de las Reinos y tierras del Rey de Aragón), La Corona de Aragón, Barcelona-Zaragoza, Editorial Aragó, S.A., 1988. 
Jaime II declara pleno jure la pertenencia de Orihuela a la Corona de Aragón, pero lo que aparece en el texto es Corona del Reino de Aragón y Reino de Aragón. En el documento 2, la presentación dice que Jaime II se obliga a que Alicante se mantenga unido a la Corona de Aragón, pero en el documento se habla de Corona de los Reyes de Aragón. El documento 3 no hace alusión a Corona de Aragón ni a fórmula parecida, hasta el punto de que en este caso la presentación tampoco lo ha hecho y no se sabe por qué se inserta lo que es el traslado notarial de una carta de Jaime II. En el documento 4, la presentación dice que Jaime II se compromete a que la villa de Guardamar se incorpore a la Corona de Aragón, pero el texto hace referencia a Corona del Reino de Aragón. El documento 5 se presenta como una vinculación a perpetuidad de los territorios que integran la Corona de Aragón, pero ni este término, ni fórmula parecida se encuentran en el texto. En el documento 7, la presentación habla de Corona de Aragón y el texto lo hace de Corona regia de Aragón. En el documento 8, frente al término Corona de Aragón pretendido en la presentación, lo que se contiene es $\mathrm{Co}$ rona regia de Aragón o regia corona nuestra. Corona regia de Aragón es el término que aparece también en el documento 9, pese a que en la presentación se sigue insistiendo en Corona de Aragón. En el documento 10 no se registra la fórmula Corona de Aragón ni otra parecida, por lo que, probablemente, en la presentación se menciona Corona sin aditamentos. Sólo en el documento 6 puede encontrarse la expresión Corona de Aragón, aunque precisamente ahí es donde la presentación no lo destaca.

De lo expuesto, resulta evidente una manipulación por parte de J.M. del Estal en la presentación del anexo documental. Salvo la licencia de traducir del latín al español, que yo también me he permitido porque no tiene consecuencias perturbadoras, J.M. del Estal debiera haber respetado en la presentación los términos que aparecen en los documentos, sin perjuicio de que en el artículo tratara de demostrar que Corona de Aragón, Corona del Reino de Aragón, Corona de los Reyes de Aragón, Corona regia de Aragón y regia corona nuestra eran expresiones oficiales equivalentes, aunque a condición, eso sí, de que no pretendiera convencernos de que es posible una confederación de varios reinos con una procuración general.

Resulta que si no me equivoco, el término Corona de Aragón sólo ha aparecido en uno de los diez documentos del anexo. Frente a esto, en dos documentos no ha aparecido Corona de Aragón ni otro término similar; $\mathrm{Co}$ rona del Reino de Aragón ha aparecido en dos documentos; Corona de los Reyes de Aragón, en uno; Corona regia de Aragón, en tres, y Corona real, en uno. Esto quiere decir que para J.M. del Estal una sola aparición del término Corona de Aragón puede servir para consagrarlo como el oficial de la forma política que han desarrollado los reyes de Aragón a partir de 1296, rechazando otros, como por ejemplo el de Corona del Reino de Aragón, el cual, al menos, ha aparecido dos veces, y el de Corona Regia de Aragón, que 
lo ha hecho tres. Esto, sin contar con que en dos documentos, el 8 y el 9, Pedro IV ha hablado de República de reinos y tierras.

Ya se comprenderá que si J.M. del Estal prescinde de la diversidad de términos y del aspecto cuantitativo en su aparición, con más razón lo hará del aspecto cualitativo. Percibe que hay un documento que es solemne, lo que no encuentra predicable de los demás, y es el documento 5, pero, entonces, es incomprensible que a J.M. del Estal no le hable el silencio de Jaime II en 1319 sobre la Corona de Aragón ratificado por Juan I en 1393. El que se considera rey de Aragón, Valencia, Cerdeña y Córcega y conde de Barcelona declara la unión perpetua e inviolable de los reinos de Aragón y de Valencia y del condado de Barcelona, aparte de los derechos que le comespondan en Mallorca e islas adyacentes, condados de Rosellón y Cerdaña, Conflent, Vallespir y vizcondados de Omelades y Carles, sobre la base de que el que sea rey de Aragón será rey de Valencia y conde de Barcelona. No ha habido momento más propicio para aplicar una denominación al conjunto y que esa denominación haya sido la de Corona de Aragón y, sin embargo, Jaime II no lo ha hecho. $i$ Cómo podemos nosotros aplicar una denominación que no ha aplicado el rey de Aragón en el momento más propicio y solemne? ¿No es incongruente hacerlo porque en otros documentos menos solemnes haya parecido una vez Corona de Aragón al tiempo que, incluso, más veces, han aparecido términos como Corona del Reino de Aragón, Corona Regia de Aragón. Corona real y República de reinos y tierras? ¿Denominaríamos España a nuestro país si la Constitución de 1978 silenciara esa palabra? Todo esto sin contar con que Jaime II ha aparecido como uno de los reyes de España sin que hayamos pretendido que España haya sido una realidad política en ese momento. Si en algo hemos de diferenciarnos Ios historiadores de los que no lo son es en la precisión de nuestro lenguaje. Uno de los mayores peligros que acechan a la historia de los pueblos que han habitado en la Península lbérica es el que procede de una terminología política sin depurar. Introducimos el caos cuando no distinguimos fuera del periodo godo entre utopía política y realidad política por lo que se refiere a España antes de finales del siglo xv, cuando sustituímos el Condado de Barcelona por Cataluña antes de finales del siglo XII, cuando desplazamos indiscriminadamente el nombre de España por el de Estado español, cuando consideramos como realidades políticas históricas las de Euskalerría y Países Catalanes, cuando sustituimos Reino de Valencia por País Valenciano, cuando denominamos Imperio español a la Monarquía Hispana o Católica, cuando denominamos Monarqufa a la castellana o a la aragonesa, cuando calificamos de confederación a la unión de reinos y tierras del rey del Aragón y cuando denominamos estados a los reinos y condados anteriores a la forma política española de los siglos $\mathrm{xIx} \mathrm{y} \mathrm{xx}^{12}$.

${ }^{12}$ Vid. La introducción a la op. cit. en segundo lugar en la nota anterior. 
No parece que el profesor J.M. del Estal participe de estos presupuestos metodológicos. Las distintas denominaciones que le ofrecen los documentos que él mismo ha seleccionado son reducidas a la única que le interesa, y que es la de la Corona de Aragón. aunque sólo la haya registrado una vez. A la Corona de Aragón la califica de confederación aragonesa sin preocuparse de explicar por qué aquélla sustituye a la confederación catalano-aragonesa, que es la que había aplicado hasta ahora parte de la historiografía, especialmente, de la historiografía catalana ${ }^{13}$. Obsesionado porque Corona de Aragón exprese una unidad territorial no duda, ni siquiera un momento, ante la posibilidad de que alguna vez pueda expresar poder en lugar de territorio ${ }^{14}$, sin tener en cuenta que términos como imperio, reino y corona han tenido originalmente un sentido estrictamente político o de calificación de un tipo de poder con ejercicio directo e indirecto del mismo, y sólo tardíamente, $y$ sin perder aquél, por laxitud en el lenguaje han podido pasar a expresar un territorio.

La indicada reducción de diversas denominaciones a una sola se le ha resistido al profesor J.M. del Estal, especialmente al encontrarse con la expresión Corona del Reino de Aragón. Ha optado por cortar el nudo gordiano sobre la base de considerar que la última expresión no se ha referido al reino individual y estricto, sino a una entidad territorial política superior $^{15}$. Ha desoído así el dicho popular de que shay que estar a las duras y a las maduras». Si para él, el hecho de que aparezca Corona de Aragón en algún documento aislado es la prueba evidente de que ésta ha sido la denominación de una forma política en ese momento, antes y después, tendrá también que pasar por el hecho de que esa Corona de Aragón se ha referido a la Corona del Reino de Aragón y nada más que a esa Corona del Reino de Aragón. Si se quiere ser fiel a los documentos, se tiene que serlo a todos. Lo que no ha sabido ver J.M. del Estal es que en todos los documentos que aporta, Corona no representa un territorio, sino una forma de poder, que es la de un rey que ha sido coronado por el Papa desde 1204 por el Reino de Aragón, sin que lo haya sido por otros reinos, como el de Valencia, por ejemplo, y menos aún por un condado, como era el de Barcelona. Ese rey sólo puede exhibir un Corona y esa Corona es la del Reino de Aragón. Por esa Corona, el rey tiene una consideración dentro de la cristiandad que no va a tener por ninguna otra tierra. Eso se ve claramente en la unión de reinos declarada por Jaime II en 1319, cuando se afirma que el que sea rey de Aragón será también rey del reino de Valencia y conde de Barcelona y no se afirma lo contrario, lo que quiere decir que el que sea Rey de Valencia no por ello será Rey de Aragón y Conde de Barcelona y

${ }_{13}^{13}$ Vid. op. cit, en nota 2, pp, 137, 139 y 140.

${ }_{14}$ No lo ha hecho, ni siquiera cuando lo que ha aparecido ha sido Corona regia en los documentos 7,8 y 9 , o Corona real en el doc. 10.

${ }^{15}$ Op. cit., p. 135. 
que el que sea conde de Barcelona no por ello será Rey de Aragón y Rey de Valencia.

El profesor J.M. del Estal manifiesta su satisfacción cuando tras buscar y rebuscar encuentra una vez la expresión Corona de Aragón y la considera diáfana como expresiva de una globalidad de territorios de lo que él denomina erróneamente una confederación, pero esa diafanidad no aparece por ningún lado. De una parte, el documento es inferior, cualitativamente hablando, a la declaración de unión por Jaime II. Esta última afecta a la estructura de la forma política y es lo que hoy denominaríamos un documento constitucional, en tanto que el documento de Alfonso IV, donde aparece el término Corona de Aragón, es la concesión de un alodio con cláusula de reversión.

$\mathrm{Si}$ a ello se añade que el propio J.M. del Estal considera que la actuación de Alfonso IV «quebrantó el compromiso sagrado de su padre», lo que significa que no la considera correcta, ya se comprenderá que será difícil que podamos considerar que Corona de Aragón ha significado una unidad territorial basándose en una sola actuación y, además, actuación incorrecta.

La diafanidad del documento procedente de Alfonso IV desaparece totalmente si se lo analiza. El rey hace donación en franco y libre alodio de un conjunto muy importante de ciudades y villas a su segundogénito, con la cláusula de que cuando se produzcan determinadas circunstancias reviertan a él o a sus sucesores y a la Corona de Aragón, con el pleno dominio y derecho que tenían antes de la donación. Si puede haber reversión a la Corona de Aragón es que ese conjunto de ciudades y villas han salido de la Corona de Aragón. Si Corona de Aragón es la unidad territorial, esas ciudades y villas habrán tenido que incorporarse a otra unidad territorial o erigirse en una forma política independiente, alternativa que es inimaginable. La reversión sólo tiene sentido si la eversión ha sido, no de la unidad territorial, sino del ejercicio directo del poder por parte del rey. Romanísticamente, podría decirse que el rey ha traspasado al segundogénito el dominio directo de esas ciudades y villas, reteniendo un dominio útil, que se manifiesta en determinadas prohibiciones de exportar y en la referida reversión por falta de descendientes. Es más, en el propio documento cuando el rey habla de su territorio no emplea Corona de Aragón, sino Reinos y tierras que tenemos o fuera de los Reinos y tierras predichas ${ }^{16}$. Esto se confirma en 1366, al establecer la inseparabilidad de Orihuela. Cuando Pedro IV se refiere a una verdadera separación territorial, como ha sido la de pasar a manos del rey de Castilla y declara la futura inseparabilidad, distingue entre Corona Regia, que representa el ejercicio de poder, y el Reino de Valencia, que representa en ese caso el aspecto territorial ${ }^{17}$. En otro

16 fd. p. 155.

17 Id, pp. 161 y 162. 
caso, la inseparabilidad de una villa respecto a la Corona Regia de Aragón no puede ser predicada sino de un poder, porque lo que no se puede hacer es adscribirla a una globalidad de territorios, sino a uno de los territorios concretos de esa globalidad.

Queda concluído así el disentimiento con un disentimiento. Yo creo que el profesor J.M. del Estal y, en general, todos los investigadores, deben estar atentos a la aparición documental del término Corona de Aragón y similares ${ }^{18}$. No tendré reparos en renunciar a mi tesis si nuevos documentos, debidamente analizados, muestran lo contrario, porque de lo que se trata es de acercarse a la verdad histórica, sin que deba ponerse en juego el amor propio. En tanto no se produzca ese acontecimiento, mi tesis, cada vez más perfilada, es la que sigue:

La realidad política de los Reinos y tierras del Rey de Aragón, calificada alguna vez de República de reinos y tierras en el siglo XIV, no ha conocido una denominación específica. Para identificar el tipo de poder y de ejercicio del mismo, los reyes de Aragón se han referido desde fines del siglo XII a la Corona del Reino de Aragón o Corona de los Reyes de Aragón, lo que, abreviadamente, se ha expresado como Corona de Aragón, Corona Regia y Corona real. A partir del interregno de principios del siglo XV se han registrado intentos de abstracción del Rey de Aragón en la Corona de Aragón, dando lugar en los siglos XVI y XVII a una alternativa conceptual entre Reinos del Rey de Aragón y Reinos de la Corona de Aragón. La abstracción Corona de Aragón se ha recuperado aisladamente a principios del siglo XvII y ha sido objeto de elaboración como realidad historiográfica en los siglos XIX y XX.

${ }^{18}$ Salvo el caso del profesor J.M. del Estal, que puede calificarse de meritorio, hay que destacar la atonía general ante un tema tan importante, como lo demuestra el que en el recientemente celebrado XV Congreso de Historia de la Corona de Aragón no se haya producido ninguna intervención en torno a él. 